\title{
Surfaces
}

Alan Malachowski, ed. Reading Rorty: Critical Responses to Philosophy and the Mirror of Nature (and Beyond). (Cambridge, Mass: Basil Blackwell, 1990), 384 pp+xiv

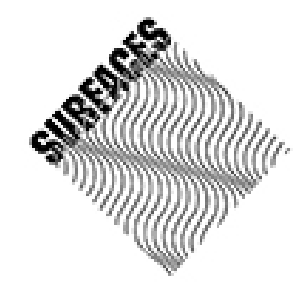

\section{Imre Szeman}

Volume 2, 1992

URI : https://id.erudit.org/iderudit/1065248ar

DOI : https://doi.org/10.7202/1065248ar

Aller au sommaire du numéro

Éditeur(s)

Les Presses de l’Université de Montréal

ISSN

1188-2492 (imprimé)

1200-5320 (numérique)

Découvrir la revue

Citer ce compte rendu

Szeman, I. (1992). Compte rendu de [Alan Malachowski, ed. Reading Rorty:

Critical Responses to Philosophy and the Mirror of Nature (and Beyond).

(Cambridge, Mass: Basil Blackwell, 1990), 384 pp+xiv]. Surfaces, 2.

https://doi.org/10.7202/1065248ar

Ce document est protégé par la loi sur le droit d'auteur. L'utilisation des services d'Érudit (y compris la reproduction) est assujettie à sa politique d'utilisation que vous pouvez consulter en ligne.

https://apropos.erudit.org/fr/usagers/politique-dutilisation/ 


\title{
BOOK REVIEW
}

\section{ALAN MALACHOWSKI: READING RORTY}

\author{
Imre Szeman
}

\begin{abstract}
Alan Malachowski, ed. Reading Rorty: Critical Responses to Philosophy and the Mirror of Nature (and Beyond). (Cambridge, Mass: Basil Blackwell, 1990), 384pp+xiv.
\end{abstract}

In the final essay of the collection Reading Rorty, Charles Guignon and David Hiley suggest that Richard Rorty's later writings (his post-Philosophy and the Mirror of Nature output) should be understood as "making explicit the moral and social commitments that have motivated his critique of epistemology-centered philosophy from the outset" (349). Viewing Rorty's work from this perspective, PMN becomes less the key to his thinking than simply the first cathartic moment in his attempt to "change the subject" (CP xiv). Critical focus on Rorty from within philosophy has long rested on the first two sections of PMN, in which Rorty shatters the mirror of nature and establishes his "epistemological behaviorism" as an alternative. But, if Guignon and Hiley are correct -- and I believe that they are -- those wishing to understand both the impetus and implications of Rorty's work would do well to begin with the third section of PMN (paradoxically entitled "Philosophy"). It is here that Rorty decisively abandons philosophy and moves to cultivate the more fertile ground of what in Consequences of Pragmatism will come to be known as "cultural" (CP xl) or "literary criticism" (CP 66). It is not that Rorty does not address himself to philosophical issues after PMN: indeed, he is all too willing to engage with philosophic objections to his work, even while attempting to "forego argumentation" (CP 142). However, Rorty's importance lies not so much in the minutiae of his philosophical views, views expressed better and less cartoonishly by others, as in the "moral" he presents: that "the attempt to gain objective knowledge of the world, and thus of oneself, [is] an attempt to avoid responsibility for choosing one's project" (PMN 361). 
It is unfortunate, however, that most philosophers, at least as exhibited by this collection, seem not to have understood the point of this "moral." Subtitled "Critical Responses to Philosophy and the Mirror of Nature (and Beyond)," the essays which Alan Malachowski has gathered together in Reading Rorty tend to focus only on the most traditionally philosophic issues addressed by Rorty in PMN. Those that do not explicitly deal with material in PMN concentrate on those aspects of Rorty's work most amenable to philosophy in Consequences of Pragmatism, and on his series of "contingency" essays (particularly "The Contingency of Language"). The rest of Rorty's corpus is consigned to the unexplored, and apparently unimportant, periphery. This lack of attention cannot simply be a matter of too little time having passed for an adequate assessment. PMN is the earliest of Rorty's post-analytic writings, and so it may seem natural that it would be the work which has attracted the most attention. However, many of the essays contained in Consequences of Pragmatism pre-date PMN, and a large number of the essays in both Contingency, Irony and Solidarity and the two recent volumes of collected papers, Objectivism, Relativism and Truth, and Essays on Heidegger and Others, date back to the early 80's The focus of the essays in Malachowski's collection thus suggests a discomfort with all but those issues which philosophers could recognize as rightly their own. With a few notable exceptions -- the essays by Charles Taylor and Nancy Fraser -- none attempt Rorty's task of seeing "how things, in the broadest possible sense of the term, hang together, in the broadest possible sense of the term" (CP xiv) with respect to the body of his own work. This is not a matter of mere quibbling. For a thinker who advocates theoria over philosophy, "taking a view of a large stretch of territory from a considerable distance" (CIS 96) over loving wisdom, some attempt should have been made to assess Rorty's work theoria-tically as well as philosophically. In focusing so narrowly on the strictly and traditionally philosophical, the essays in this collection not only fail to address the scope of Rorty's position, but also inadvertently reinforce his description of philosophy as a discipline intractably haunted by the spectres it sees reflected in the mirror of nature.

Setting these general misgivings aside, the essays in this collection effectively, if narrowly, offer philosophical criticisms of Rorty's various positions. In the opening essay, Tom Sorrel argues that Rorty misrepresents the notion of objectivity when he suggests that it is talk about "what the world is like in itself"(12). Sorrell argues that a claim of objectivity is simply a suggestion of what kind of world -- outside and separate from us -- is necessary to account for different subjective representations. This is why not every clash -- for example, between Aristotle and Newton -- is, in Rorty's sense, a clash of vocabularies, but rather a clash of theories, i.e., a clash between conceptions of a world independent of us in which there is a clear victor -- that theorywhich helps us to advance our knowledge of the world. In "Auto-de-Fe: Consequences of Pragmatism," Bernard Williams suggests that conversational constraints of the sort exemplified by Habermas' formulation of an "ideal speech situation" are necessary if the "conversation of mankind" is to be saved from mere anarchy and the rule of the powerful. While analytic philosophy's may be unable to find criteria by which all discourses 
might be rendered commensurable, it nonetheless offers an "example of certain virtues of civilized thought" (35) -- constraints of rational consistency, explicitness, and clarity - -- which are important if "mere rhetoric and the power of words"(35) are not to prevail. In William's view (a position reiterated by Jo Burrows and Martin Hollis), Rorty cannot then so simply abandon philosophy if he hopes to keep a liberal, post-philosophical culture intact. It is, for Williams, "excessively optimistic" to suppose that without the constraints exemplified by philosophy, liberal "traditions of openmindedness and receptiveness to new considerations" will necessarily be sustained (35).

Jennifer Hornsby's "Descartes, Rorty, and the Mind-Body Mind" argues that Rorty overstates his objection to the "mind" by focusing only on the phenomenal items of the mind ("raw feels," pain, etc.), thereby failing to account for intentional items. This leaves room for at least a limited concept of the mind, since "resistance to a Cartesian view of the mind need not be resistance to the whole phenomenon of the mind, but only to a conception of the mental informed by a particular view of what the natural world can contain" (56). John Yolton, while not disagreeing with Rorty's depiction of philosophy's fascination with the mirror of nature, wishes to defend Descartes and Locke against those stereotypes which suggest that they originated the view of the mind as a mirror. What has been forgotten, Yolton asserts, is that talk of mirrors, blank tablets, camera obscura, etc, were for Descartes and Locke metaphors used "in lieu of an existing psychology vocabulary" (69). Gerald Vision, David Houghton and Michael Clark offer challenges to Rorty's views on correspondence and reference, and Donald Davidson and W.V. Quine provide essays intended as correctives to Rorty's idiosyncratic appropriation of their views. As Malachowski writes in his introduction, the "general worry" that all these authors share is that "the issues raised by the sort of philosophy Rorty attacks are not the sort of issues which can simply be dropped from the intellectual menu" (6).They thus unsurprisingly end with the common suggestion that their particular criticisms of Rorty reinforce the need for philosophy. Yet, by capturing too small a slice of what he says, and by failing to clarify how the particular points they make frustrate Rorty's anti-philosophical message, none of these essays offer either an adequate defense of philosophy or a serious criticism of Rorty's position as a whole.

A powerful critique of Rorty's stance toward philosophy is, however, offered by Charles Taylor. In "Rorty in the Epistemological Tradition," Taylor suggests that Rorty's efforts to reject the epistemological tradition remain ineluctably trapped within this tradition. Taylor argues that Rorty has developed a "global ex ante" theory of knowledge which decides- -without appeal to particular cases - -- that alterative vocabularies are necessarily "mutually immune to refutation" (268). For Taylor, such a theory arises from the fact that Rorty, as much as he would wish to deny it, is still commanded by a (roughly) Kantian epistemological framework. Rorty's challenge to philosophy, and his consequent suggestion that a number of incommensurable vocabularies can exist side-by-side, rests on the 
supposition that since we can no longer assume that there are things-inthemselves to arbitrate different views, then it is possible that all views may be fundamentally incompatible. Taylor also offers a perceptive diagnosis of a problem which troubles a number of the contributors to this collection. Michael Clark identifies this problem as the "fundamental paradox of pragmatism": "if it is right, then how can we know, how can Rorty be so sure it is right" (181)? Taylor describes this paradox as a case in which the "metaissue" -- for Rorty, the fact that alternative vocabularies are incommensurable -- is made to be an instance of its own undecidability. As with Descartes' establishment of a method of certainty whose certainty can itself only be guaranteed by the method, so, too, for Rorty, the pragmatic celebration of contingency renders this celebration contingent itself. Taylor argues that in any theory, the meta- issue should be decided upon before it is turned back upon itself. Otherwise, as Clark points out, "applied to itself, his [Rorty's] pragmatism is self-defeating. And by what divine right does it escape self-application?" (181)

It is the essays by Jacek Holöwka and Martin Hollis which begin to reveal the essential tensions at the core of Rorty's project. Both suggest that Rorty's "epistemological behaviorism" and his concern with self-creation are positions that are fundamentally at odds. In "Philosophy and the Mirage of Hermeneutics," Holöwka points out that because a strong behaviorist theory threatens the idea of "choice" in the sense in which this is normally understood, Rorty "cannot have the atoms-and-the-void theory which explains everything and also say that you have reality-under-a-certaindescription" (191), a suggestion echoed by Jane Heal in "Pragmatism and Choosing to Believe." Hollis makes much the same point in "The Poetics of Personhood," suggesting that "active spinners" are required for the spinning of a web-of-belief. Epistemological behaviorism, however, allows spinning only in the "passive voice" (247). This passivity means as well that Rorty's behaviorism negates the import he appears to place on moral choice with regards to such matters as distinguishing between better and worse communities, one's solidarity to one's community, and the proclivity to limit cruelty. Holöwka raises the further point that since any predictive model based on epistemological behaviorism would be both impossibly complex and open in any particular instance to easy falsification, that such a theory, rather than eliminating cruder, more clumsy models of the mind, in fact reinforces their necessity (192-3). Such a model of the mind need not be of the "glassy essence" sort, but could be the models used (for example) in psychoanalysis, clinical psychology or neurology (193). However, it seems to me that the suggestion that there is an essential tension between selfcreation and epistemological behaviorism is somewhat misplaced. Why, for example, could choice not be the outcome of an extremely complex set of behavioristic conditions and still retain the quality of a "free" choice? That it could not seems to be a more a matter of philosophy's historical framing of this question as a choice between an atoms-and-void description of things or the possibility of free will, as opposed to something essential to the character of choice.[1] Holöwka and Hollis are wrong, then, to point out that there is something inherently contradictory in a view which simultaneously 
suggests the possibility of the scientific prediction and control of human beings, and yet insists on celebrating their autonomy and individuality.

In many ways, the task of reconciling epistemological behaviorism and selfcreation nonetheless dominates -- if in a modified form -- Rorty's latest work. The concern is no longer to bridge epistemological behaviorism and selfcreation (indeed,it may be said that for Rorty this never was a concern), but to reconcile the seemingly disparate realms of public solidarity -epistemological behaviorism reflected into the social- -and private selfcreation. Rorty values the romantic ethic of private self-creation as exemplified in the work of poets and revolutionary thinkers. It is these romantic figures who, in an attempt to evade description by the vocabularies of their communities, struggle to create new vocabularies which capture their particular, idiosyncratic, "lading lists," thereby ensuring that they are not simply "dying animals." It is also the romantic who, by creating new vocabularies, acts as the motor of historical change: the vocabularies in which they redescribe themselves, provide the ever evolving terms in which "we" might similarly attempt to redescribe ourselves as more than simply members of a pack. Rorty is wary, however, of the fact that private selfcreation, untempered by a sense of social solidarity, is susceptible to political excesses which may become cruel, harmful, or even fascistic. So his task becomes the articulation of a romantic impulse which is also liberal, democratic, and pragmatic, without these social elements dulling the sharpness of the romantic's "ironism" -- her sense that the terms in which she describes herself are always open to change.

Nancy Fraser's essay, "Solidarity or Singularity? Richard Rorty between Romanticism and Technocracy," examines the ways in which Rorty has attempted to reconcile these "romantic" and "pragmatic" impulses present in his writing. Fraser identifies three stages in this attempted reconciliation. In the first, "invisible-hand" stage, the romantic impulse fosters liberal values such as kindness and decency (307). By disenchanting the world, romanticism promotes tolerance and social justice. However, since "there is no logical entailment between anti- essentialism and loyalty to one's society" (308) (the worry expressed earlier by Burrows, Hollis and Williams), Fraser suggests that Rorty, in his "sublimity or decency" stage, comes to wonder whether romanticism can in fact be compatible with decency. Solidarity involves affiliation to a community; romanticism, on the other hand, is a parasitic, selfish disaffiliation which might lead to elitism and cruelty. It would seem, then, that ultimately a choice must be made between the romantic and the pragmatic. Rather than choose between them, however, Rorty assigns these impulses to different spheres: the private and the public. In this third, "partition" stage, self-creation and solidarity need not be inextricable opposites, so long as we remember that "when irony goes public, it gets into trouble" (311). 
As both Fraser and Jo Burrows point out, the division of pragmatism and romanticism into public and private has the unintended effect, pace Rorty, of reducing vocabularies and silencing the "conversation." This is due to the fact that for Rorty "radical thought" -- political theory influenced by Marx, Adorno, Althusser, Derrida, Foucault, Lacan, etc. -- "has no political implications" (311). Any use of these radical thinkers, and others like Heidegger and Nietzsche, is confined by Rorty to the private realm of selfcreation: the romantic goals of self- invention may be appropriate to individuals, but if applied to societies may result in a "political attitude" in which we come to think that "there is some social goal more important than avoiding cruelty" (CIS 65). This limitation of radical thought de- politicizes both culture and theory, for in Rorty's schema "there can only be apolitical ironist theory and atheoretical reformist practice" (314). It also means that "non-liberal, oppositional discourse" (315) becomes by definition nonpolitical as well, representing either a retreat from solidarity or a political position which is hopelessly metaphysical. For Fraser, Rorty's strict distinction between public and private rules out many of the features we might want to preserve in our social and political landscape. For example, the public/private division does not permit there to be a political (as opposed to a private) impetus for the creation of new vocabularies, a place for communities (as opposed to individuals) which might have non- liberal vocabularies, and the possibility of political assessments in terms other than Rorty's own peculiar blend of pragmatism and liberalism. It also fails to note that much of what liberalismhas historically considered to be private (the economic, the domestic, the medical, the educational, etc.) has, as a result of radical thinkers, been shown also to be power-laden and political, and thus public as well (312). There are good grounds, then, for Burrows' view of Rorty as a liberal-apologist peddling liberal-ideology. As she suggests, "despite gestures toward 'openness,' 'pluralism, ' 'sensitivity to persuasion,' and so on, the liberal set-up as apologized for by Rorty does not cater for the political contender" (332). It is thus not at all clear that liberalism of the sort Rorty describes is in fact the best pragmatic option available given current historical circumstances. Rorty's "partition" solution to problem of bringing together the romantic and pragmatic appears to endanger the evolution of social solidarity more than it extends "our sense of 'we' to people we have previously though of as 'they"' (CIS 192). However, if we view Rorty's public/ private distinction as a concrete, political suggestion as opposed to a theory of the political - -- that is, as "policing" rather than depoliticizing culture and theory - -- the criticisms offered by Fraser and Burrows seem to be somewhat immaterial.

Fraser and Burrows locate Rorty's difficulty in reconciling the romantic and the pragmatic on the side of the political. If there is anything which problematizes this rapprochement, however, I think one has to look beyond the ideology of Rorty's comfortably liberal, frankly ethnocentric politics, to his benign treatment of irony, and thus of the romantic temperment as well. Rorty underestimates the eroding power of the irony he associates with romantic intellectuals. Irony places the intellectual in a position that Rorty, following Sartre, calls "meta-stable" -- a position in which intellectuals are 
"never quite able to take themselves seriouly because always aware that the terms in which they describe themselves are subject to change, [they are] always aware of the contingency and fragility of their final vocabularies and thus of their selves" (CIS 73-4). There are two difficulties with such a view. One is touched upon by Bernard Williams when he suggests that Rorty "neglects the question whether one could accept his account of various intellectual activities, and still continue to practice them" (29).

How, or why, could an ironist -- always aware of the impermanence of every vocabulary -- ever be beguiled enough by any particular vocabulary to allow it to become her vocabulary, for whatever brief period of time? The second difficulty lies in the fact that the ironist's doubt concerning the limitations of her own vocabulary is a doubt which quickly becomes all-consuming: irony turns on irony, meta-stability becomes radical instability. This is not to deny Rorty's historicist point that "a belief can still regulate action, can still be thought to be worth dying for, among people who are quite aware that this belief is caused by nothing deeper than contingent historical circumstance" (CIS 189). It is to ask, however, whether the ironist belongs among such people. In being consumed by irony, in becoming completely ironic, the ironist displaces herself from concern with practical beliefs. To be an ironist means to be paralysed when it comes to the pragmatic activity demanded in one's involvement in the liberal state. This more threatening, less benign sense of irony that I have been discussing here, is described by Paul de Man (who should know) in "The Rhetoric of Temporality":

Irony divides the flow of temporal existence into a pastthat is pure mystification and a future that remains harassed forever by a relapse within the unauthentic. It can know this unauthenticity but can never overcome it. It can only restate and repeat it on an increasingly conscious level, but it remains endlessly caught in the impossibility of making this knowledge applicable to the empirical world. It dissolves in the narrowing spiral of a linguistic sign that becomes more and more remote from its meaning, and it can find no escape from this spiral (de Man, 222).

Rorty's view of irony shares many features with de Man's. Like de Man, irony for Rorty occupies a temporally mediate place between mystification (the old vocabulary) and the knowledge that no new vocabulary will ever serve as an authentic one (though Rorty, unlike de Man, would be uncomfortable in describing this place in terms of "mystification" and "authenticity"). Irony is for Rorty also inapplicable to the "empirical world": it must remain confined to the private lest it overstep its bounds. For Rorty, the inability to apply irony to the public sphere is a condition of irony; for de Man, however, irony's empirical impotence arises from the ironist's obsessive pre-occupation with her inability to take any decisive action which would ever be more than purely and radically contingent. Unlike Rorty, de Man suggests, then, that irony cannot simply be "turned off" once one 
wishes to abandon the role of the romantic and join the world of pragmatic activity. For,

at the very moment that irony is thought of as knowledge able to order and cure the world, the source of its invention immediately runs dry. The instant it construes the fall of the self as an event that could somehow benefit the self, it discovers that it has substituted death for madness (de Man, 218).

If we accept this more threatening, less benign reading of irony, then it does not seem as if one could be a pragmatist by day and a romantic ironist by night. This is not to say that we cannot express scepticism about our vocabularies, or worry that we might have been born into the wrong tribe. What distinguishes "the urbane, sceptical person in a liberal society, who simply asserts things like: 'Everything is relative"' (327) from the ironist is not this healthy scepticism, but the fact that when we discuss the ironist -those brilliant, neurotic individuals who go about redescribing themselves -we usually do so with the added caveat that while they might be nice to visit, we would not want to be them -- individuals trapped and confined by contingency, as opposed to gaining freedom through and by means of it.

Rorty's work is, if anything, a call to free ourselves through an understanding of the contingency of our beliefs, histories, and communities -- the contingency of the web of beliefs which makes us the kind of selves we are. This includes, most importantly for Rorty, freeing ourselves of philosophy, an activity which opposes and fears contingency. It is only by accepting contingency, after all, that we can take up the romanticist task of re-fashioning ourselves for ourselves, and not in reference to some ideal standing outside and above us. As I have tried to suggest above, this ironic reshaping may be, as genius is, to "madness near allied," and is thus perhaps a difficult task to imagine as the aim of intellectual activity. And yet, if there is anything which is lacking in Reading Rorty, it is precisely a lack of such madness, a refusal to be drawn -- however slightly, however briefly - -out of philosophy and into the difficult terrain of self-description. It is this failure to reflect on the activity of philosophy, and the unproblematic insistence on doing "business as usual," which marks in these essays the failure of philosophy to engage, however Iimitedly, with the main impetus behind Rorty's thought.

\section{Imre Szeman}

\section{Department of Comparative Literature}


Surface Page d'Acceuil/Home Page

\section{Works Cited}

de Man, Paul. "The Rhetoric of Temporality." Blindness and Insight. Second, revised ed. Theory and History of Literature 7. (Minneapolis: U of Minnesota Press, 1983), 187-228.

Dennett, Daniel C. "Self-Made Selves." Elbow Room: The Varieties of Free Will Worth Wanting. Ch. 4. (Cambridge, Mass.: The MIT Press, 1984), 74100.

Rorty, Richard. Philosophy and the Mirror of Nature. (Minneapolis: U of Minnesota Press, 1979), (PMN).

. Consequences of Pragmatism. Minneapolis: (U of Minnesota Press, 1982), (CP).

. Contingency, Irony, and Solidarity. (Cambridge: Cambridge UP, 1989), (CIS).

[1]See, for example, Dennett 1984. Dennett contests the view that "if we are mere conduits of causation...we cannot also be agents" (76). That we are such conduits seems to suggest that we are "mere dominoes" rather than "moral agents." As Dennett points out, however, unlike dominoes, we are conduits of causation that are capable of significant self-improvement, have an "open-ended capacity for 'radical self-evaluation'," and have the "property of being caused to have reliable expectations about what will happen next, and hence to have the capacity to control things" (100). For Dennett, the view that causation and moral agency are fundamentally at odds stems from "our taking a good idea, the idea of the self as a unitary and cohering point of view on the world, and pushing it too far under the pressure. 